\title{
Thermodynamic studies on the adsorption behavior of ammonium on zeolite
}

\author{
Vira Sabadash ${ }^{1}$, Jaroslaw Gumnitsky ${ }^{2}$, Taras Hertsyk ${ }^{3}$ \\ 1. Department of Ecology and Sustainable Environmental Management, Lviv Polytechnic National University, \\ UKRAINE, Lviv, St. Yura Square 3/4, E-mail: virasabadash@ gmail.com \\ 2. Department of Ecology and Sustainable Environmental Management, Lviv Polytechnic National University, \\ UKRAINE, Lviv, St. Yura Square 3/4, E-mail: jgumnitsky@ukr.net \\ 3. Department of Ecology and Sustainable Environmental Management, Lviv Polytechnic National University, \\ UKRAINE, Lviv, St. Yura Square 3/4, E-mail: tarashertsyk @ gmail.com

\begin{abstract}
- the present article substantiates the thetmodynamics of adsorption on zeolite. Thermodynamic parameters were obtained. It was found that the adsorption of ammonium chloride onto natural zeolite was an exothermic and spontaneous process. Thermodynamic parameters including changes in the enthalpy $\left(\Delta H_{0}\right)$,entropy $\left(\Delta S_{0}\right)$ and Gibbs standard free energy $\left(\Delta G_{0}\right)$ were calculated.
\end{abstract}

Keywords - adsorption, zeolite, ammonium, thermodynamics, external diffusion.

\section{Introduction}

The problem of the thermodynamic description of the adsorption process in liquid phase at present is not resolved compleatly, despite intensive research in this field [1,2]. There are many models describing the thermodynamics of the process of adsorption from the gas environment. Most mathematical dependencies are empirical and relate solely to experimental data. The only possibility for the solution of adsorption problems is the two-component solution-solid solution sorbent system at constant temperature and pressure. It is assumed that the adsorbent has been pre-saturated with a solvent and that the change of Gibbs standard free energy is caused by displacement of the solvent from the volume of the sorbent equivalent to the amount of the dissolved substance.

\section{Experimental}

The effect of temperature on the time dependence of the adsorption process of ammonium onto natural zeolite was studied in static isotermic conditions. To determine the adsorption capacity of zeolite in relation to ammonium ions, glass flasks were placed in $200 \mathrm{ml}$ of $\mathrm{NH}_{4} \mathrm{Cl}$ solution prepared in distilled water at different initial concentrations $(C=0.1-1 \mathrm{~g} / 1)$, and the same amounts of adsorbent were added. The concentration range corresponded to ammonium concentration in the actual wastewater. The flasks were sealed and left at intermittent stir for two days at $+20^{\circ} \mathrm{C}$. The sorbent was separated from the solution, which was analyzed for the content of ammonium ions by the photoelectrocolorimeter according to the known method $[1,3]$.

To determine the regularities of the interaction of aqueous ammonium chloride solution with the surface of aluminum oxide, we calculate the change in the standard Gibbs energy [10].

$$
\Delta G_{0}^{298}=\Delta \mathrm{H}_{0}^{298}-T \Delta S_{0}^{298} \frac{k J}{m o l \cdot K}
$$

The state of equilibrium of the thermodynamic system is due to the ratio of entropy and enthalpy factors. At the temperature level $=\mathrm{dH} / \mathrm{dS}$ the system will be in equilibrium state.

Since entropy is a function of the state, its change as a result of the chemical reaction is equal to the difference in the entropy of the formation of the reaction products and the starting substances: 


$$
\Delta \mathrm{S}_{0}^{298}=\sum \Delta \mathrm{S}_{0}^{298}-\sum \Delta \mathrm{S}_{0}^{298}, \frac{k J}{\mathrm{~mol} \cdot K}
$$

According to Gess's law, we expect the thermal effect of the reaction:

$$
\Delta H_{0}^{298}=\sum \Delta H_{0}^{298}-\sum \Delta H_{0}^{298}, \frac{\kappa Д ж}{\text { моль } \cdot K}
$$

Under standard conditions ( $\mathrm{T}=298 \mathrm{~K}$ ), the change in Gibbs energy depends on the ratio of enthalpy and entropy factors.

Thermodynamic parameters such as changes in the standard free energy $(\Delta G 0)$, enthalpy $(\Delta H 0)$ and entropy $(\Delta S 0)$ were calculated using following equations [4]:

$$
\begin{aligned}
& K_{c}=\frac{\mathrm{a} * / \varepsilon}{\mathrm{C}} \\
& \Delta G=-R T \ln K_{c} \\
& \ln K_{c}=\frac{\Delta S^{0}}{R}-\frac{\Delta H}{R T}
\end{aligned}
$$

where $K_{C}$ is the equilibrium constant, a* is the amount of adsorbate on the adsorbent per $1 \mathrm{~g}$ of zeolite of the solution at equilibrium $(\mathrm{g} / \mathrm{g}), \varepsilon$ - porosity; $C$ the equilibrium concentration of ammonium ions in the solution $\left(\mathrm{mg} / \mathrm{dm}^{3}\right)$. $\mathrm{T}$ is the solution temperature $\left({ }^{\circ} \mathrm{K}\right)$ and $\mathrm{R}$ is the universal gas constant and $\mathrm{R}=8,314 \mathrm{~J} / \mathrm{mol} \cdot \mathrm{K}$.

\section{Results and interpretation}

We carried out studies on adsorption of ammonium ions on a natural zeolite on various temperatures. The uptake of Ammonium increased with increasing temperature at the same adsorption time. The shape of the adsorption curves at different temperatures; 288, 293, and 303 $\mathrm{K}$,

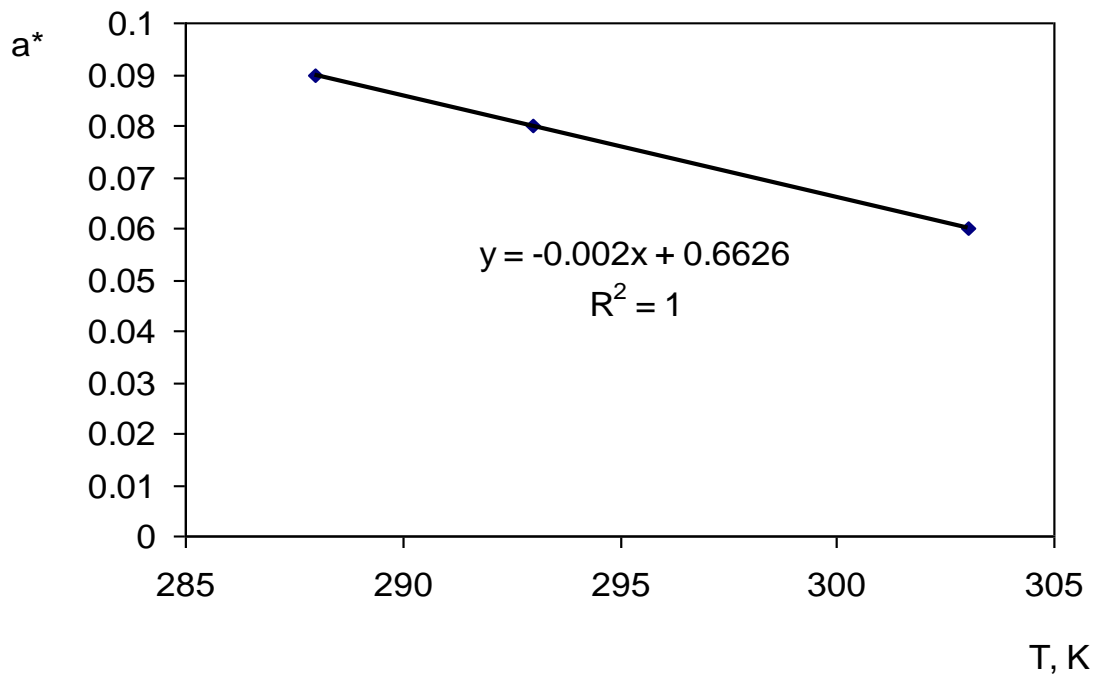

Fig.1 Effect of temperature on $\mathrm{NH}_{4}{ }^{+}$ion adsorption onto zeolite 


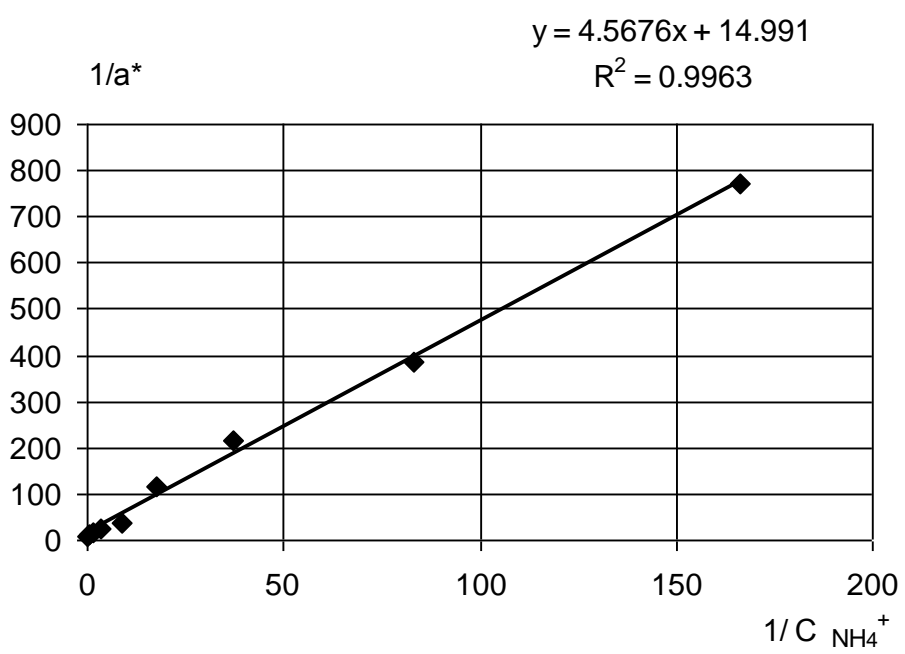

Fig.2. Interpretation of experimental data to the Langmuir isotherm

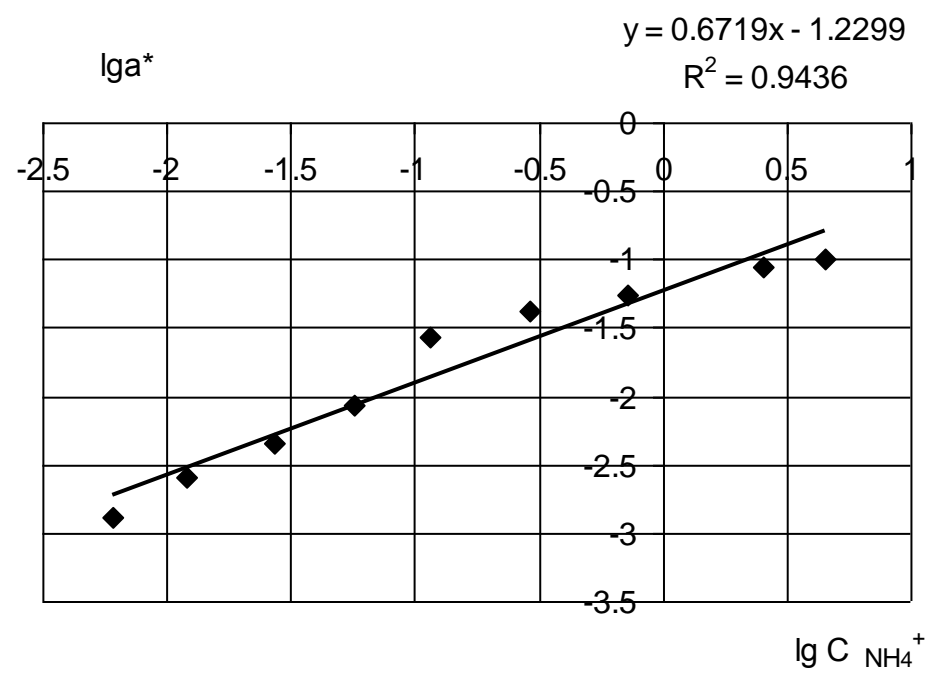

Fig.3. Interpretation of experimental data to the Freundlich isotherm

The amount of ammonium ions exchanged at equilibrium at different temperatures of 15 , 20 and $25^{\circ} \mathrm{C}$ was used to calculate and obtain thermodynamic parameters.

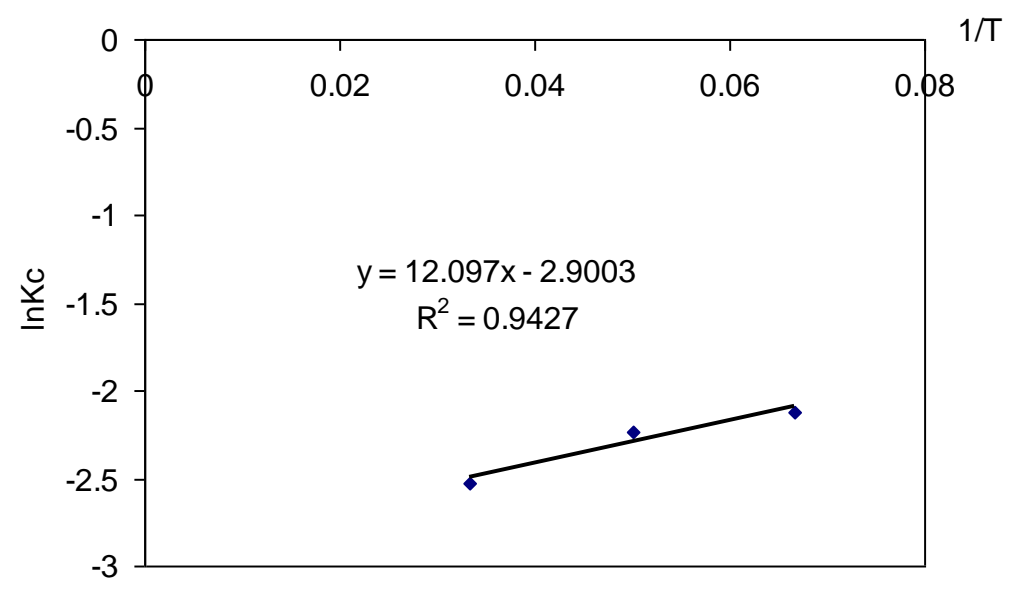

Fig.4 Dependence of equilibrium constant $\left(\mathrm{K}_{\mathrm{C}}\right)$ to temperature of adsorption process 
$\Delta H_{0}$ and $\Delta S_{0}$ were calculated from the slope and intercept of linear plot of $\ln K_{C}$ versus $1 / \mathrm{T}$ (as shown in Fig. 4).

The calculated values of $K_{C}, \Delta G_{0}, \Delta H_{0}$ and $\Delta S_{0}$ parameters were presented in Table 1.

Change in the standard free energy $\Delta G_{0}$ with negative values for $-5.08,-5.45$ and -6.72 $\mathrm{kJ} / \mathrm{mol}$ at all the experimental temperature indicates that ammonium exchange by zeolite is spontaneous. Furthermore, ammonium ion exchange process has physical characteristics since the Gibbs free energy change is between 0 and $-20 \mathrm{~kJ} / \mathrm{mol}[4,5]$.

Change in the standard enthalpy $\Delta H_{0}$ has a value of $-0,101 \mathrm{~kJ} / \mathrm{mol}$. The negative $\Delta H_{0}$ exhibits that the process of $\mathrm{NH}_{4}{ }^{+}$ion exchange by zeolite is exothermic. The negative value of the standard entropy change $\Delta S_{0}(-0,034 \mathrm{~J} / \mathrm{K} \mathrm{mol})$ indicates that the randomness decreases with the removal of ammonium ions on zeolite.

Table 1

Change of thermodynamic parameters with temperature

\begin{tabular}{|c|c|c|c|c|c|c|c|}
\hline $\mathrm{T}, \circ \mathrm{K}$ & $1 / \mathrm{T}$ & $a^{*}, g / g$ & $\mathrm{Kc}$ & $\ln K c$ & $\begin{array}{l}\Delta G_{0,} \\
\mathrm{~kJ} / \mathrm{mol}\end{array}$ & $\begin{array}{l}\Delta S_{0,}, \mathrm{~J} / \mathrm{K} \\
\mathrm{mol}\end{array}$ & $\begin{array}{l}\Delta H_{0}, \mathrm{~kJ} / \\
\mathrm{mol}\end{array}$ \\
\hline 288 & 0.06 & 0.09 & 0.11 & -2.12 & -5.08 & & \\
\hline 293 & 0.05 & 0.08 & 0.106 & -2.23 & -5.45 & & \\
\hline 303 & 0.033 & 0.06 & 0.08 & -2.52 & -6.36 & -0.034 & -0.101 \\
\hline
\end{tabular}

Conclusion

The adsorption process was shown to be an efficient for ammonium ions removal from water solutions. The results clearly demonstrated that natural zeolite contributed to the adsorption mechanism through ion exange mechanism. The percentage uptake of dyes is concentration dependent; decreasing with an increase in dye concentration. The equilibrium adsorption behavior of ammonium ions onto zeolite the Langmuir and Freundlich adsorption isotherms. The adsorption of ammonium ions on zeolite is a spontaneous and exothermic process.

\section{References}

[1] H. I. Yang, K. Lou, A. U. Rajapaksha, Y. S. Ok, A. O. S. X. Anyia, Chang Adsorption of ammonium in aqueous solutions by pine sawdust and wheat straw biochars. Environmental Science and Pollution Research, 2018, pp.25638-25647.

[2] D. W. Breck, Zeolite Molecular Sieves: Structure, Chemistry and Use, Wiley, New York, USA, 1974, 784p.

[3] Z. Zhou, J. Yuan, M. Hu, Adsorption of ammonium from aqueous solutions on environmentally friendly barbecue bamboo charcoal: characteristics and kinetic and thermodynamic studies. Environmental Progress \& Sustainable Energy, 2015, pp.655-662.

[4] H. Zheng, L.Han, H. Ma, Y. Zheng, H. Zhang, D. Liu, S. Liang, Adsorption characteristics of ammonium ion by zeolite 13X. Journal of hazardous materials, 2008, pp.577-584

[5] V.V. Sabadash, J.M. Gumnitsky, O.V. Lyuta, I. Pochapska, Thermodynamics of $\left(\mathrm{NH}_{4}^{+}\right)$ cation adsorption under static conditions. CHEMISTRY \& CHEMICAL TECHNOLOGY, 2018, pp.143-146. 